\title{
A new type of inorganic binder curing agent for soft soil
}

\author{
Airong Zheng ${ }^{1,2,3,4^{*}}$ \\ ${ }^{1}$ CCCC Tianjin Port Engineering Institute Ltd., Tianjin, 300222, China \\ ${ }^{2}$ Key Laboratory of Geotechnical Engineering, Ministry of Communications, Tianjin, 300222, China \\ ${ }^{3}$ Key Laboratory of Geotechnical Engineering of Tianjin, Tianjin, 300222, China \\ ${ }^{4}$ CCCC First Harbor Engineering Company Ltd., Tianjin, 300461, China
}

\begin{abstract}
Aiming at the defects of traditional curing agent in strengthening soft clay, a new type of inorganic binder type soil curing agent has been developed. Compared with P.O 42.5 cement, the new soil stabilizer has smaller fineness and larger specific surface area. The strength of the soil solidified by the new curing agent is lower at the initial stage, but it increases rapidly after 24 hours. When the dosage is $10 \%$, the 28-day strength of the soil solidified by the new curing agent is 2.1 times that of the soil solidified by cement. The soil solidified by the new curing agent can form more calcium hydroxide crystals and hydrated calcium silicate gel with more compact structure. After solidification, there are fewer fine particles in the soil.
\end{abstract}

\section{Introduction}

Since the 1950s, soil stability has been studied as a subject. The principle of soil stability is to use a curing agent to improve the physical and mechanical properties of the soil to meet the needs of engineering technology. The most commonly used curing agents are cement, lime and fly ash. In the past two decades, with the rapid development of soil solidification technology, a variety of curing agents have been developed ${ }^{[1,2]}$. The curing agent has developed from a single inorganic binder into a variety of complex and comprehensive chemical substance ${ }^{[3-5]}$. However, the reinforcement effect varies greatly. Especially when strengthening super soft soil with high water content and fine soil particles, there are many problems such as high dosage of curing agent, low strength and poor uniformity of reinforced soi ${ }^{[6-8]}$. In order to solve this problem, a kind of economic solidifying agent for soft soil was developed.

\section{Material properties of new curing agent}

The new curing agent is a kind of inorganic binder curing agent which is grinded by a variety of cementbased materials. This kind of curing agent is solid powder generally, including main curing agent and auxiliary curing agent. The main curing agent includes cement, lime, fly ash, various slag, coal gangue, etc. Curing aids include acids, sulfates, other inorganic salts and a small amount of surfactants as activators.

The particle size and gradation of inorganic binder have great influence on hydration and hardening rate, water demand, workability, exothermic rate, especially on the strength of solidified soil. The overall thickness of the cured material is expressed by fineness. The finer the particle is, the larger the surface area of the reaction with water is, so the hydration reaction is faster and more complete, and the early strength is higher, but the hardening shrinkage in air is larger, and the cost is higher. The coarseness of the particles is not conducive to the activity of the cured materials. Taking cement as an example, generally, when the particle size is $0-10 \mu \mathrm{m}$, the hydration is the fastest, when the particle size is 3$3 \mu \mathrm{m}$, the activity is the largest, when the particle size is greater than $60 \mu \mathrm{m}$, the activity is smaller, and the hydration is slow. When the particle size is greater than $90 \mu \mathrm{m}$, the hydration can only be carried out on the surface, playing the role of micro aggregate. Therefore, in general, in order to give full play to the cementitious properties of the cured materials and improve the early strength of the cured materials, it is necessary to improve the fineness of the cured materials and increase the gradation ratio of 3 to 30 microns.

However, if the curing material is too fine, the specific surface area is too large, with too many particles smaller than 3 microns, the water demand of the curing material is too large, which will cause the increase of porosity and decrease the strength of the hardened material paste due to too much water. At the same time, the fineness of the cured material will also affect other properties of the cured material. For example, the activity of the cured material during the storage period decreases rapidly, the water demand of the cured material is greater, the shrinkage of the cured material product increases, and the frost resistance decreases. In addition, if the curing material is too fine, it will significantly affect the performance of the curing material grinding equipment, which will reduce the

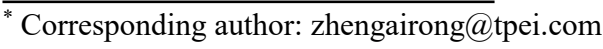


output and increase the power consumption. Therefore, the fineness of the cured material must be reasonably controlled in the production, so that the cured material has a reasonable particle gradation.

Therefore, the particle size of the new curing agent is smaller to obtain larger specific surface area. The specific surface area, fineness and particle composition of the cured materials were determined by using specific surface area tester, negative pressure screen and laser particle size distribution instrument (dry method). The test results are shown in Table 1 and table 2. The specific surface area of the new curing agent is significantly higher than that of P.O 42.5 cement, and the content of particles smaller than $3 \mu \mathrm{m}$ and $10 \mu \mathrm{m}$ is slightly higher than that of cement, which can make the curing agent have better hydration performance.

Table 1. Specific surface area and fineness

\begin{tabular}{|c|c|c|c|}
\hline \multirow{2}{*}{ material } & \multicolumn{2}{|c|}{ specific surface area $\left(\mathrm{m}^{2} / \mathrm{g}\right)$} & \multirow{2}{*}{ fineness } \\
\cline { 2 - 3 } & $\begin{array}{c}\text { specific } \\
\text { surface } \\
\text { area tester }\end{array}$ & $\begin{array}{c}\text { laser particle size } \\
\text { distribution } \\
\text { instrument }\end{array}$ & \\
\hline $\begin{array}{c}\text { new soil } \\
\text { stabilizer }\end{array}$ & 0.387 & 0.370 & 11.6 \\
\hline $\begin{array}{c}\text { P.O 42.5 } \\
\text { cement }\end{array}$ & 0.322 & 0.301 & 12.0 \\
\hline
\end{tabular}

Table 2. Particle composition (\%)

\begin{tabular}{|c|c|c|c|c|c|}
\hline material & $\leq 3 \mu \mathrm{m}$ & $\leq 10 \mu \mathrm{m}$ & $\leq 30 \mu \mathrm{m}$ & $\leq 60 \mu \mathrm{m}$ & $\leq 90 \mu \mathrm{m}$ \\
\hline $\begin{array}{c}\text { new soil } \\
\text { stabilizer }\end{array}$ & 13.68 & 37.15 & 74.36 & 94.7 & 99.15 \\
\hline $\begin{array}{c}\text { P.O 42.5 } \\
\text { cement }\end{array}$ & 11.09 & 30.4 & 67.62 & 90.77 & 97.3 \\
\hline
\end{tabular}

\section{Properties of solidified soil}

\subsection{Mix proportion test scheme}

In order to test the curing performance of the new curing agent, a comparative test was carried out with P.O 42.5 cement. The test soil was dredger fill in Tianjin port, and its performance indexes are shown in Table 3 . The dosage of cement and curing agent was $6 \%, 8 \%$ and $10 \%$, and the water cement ratio was 1.0. The cylindrical samples were $10 \mathrm{~cm}$ high and $5 \mathrm{~cm}$ in diameter. The samples were placed in an environment with a temperature of $(20 \pm 3){ }^{\circ} \mathrm{C}$ and a relative humidity of greater than $90 \%$ for 24 hours, then the molds were removed, and the curing was continued in this environment.

Table 3. Characteristics of test soil

\begin{tabular}{|c|c|c|c|c|c|c|}
\hline$\omega(\%)$ & $\mathrm{G}_{\mathrm{s}}$ & $\rho\left(\mathrm{g} / \mathrm{cm}^{3}\right)$ & $\omega_{\mathrm{L}}(\%)$ & $\omega \mathrm{P}(\%)$ & $\mathrm{IP}_{\mathrm{P}}$ & $\mathrm{IL}_{\mathrm{L}}$ \\
\hline 56.5 & 2.75 & 1.68 & 41.8 & 20.7 & 21.1 & 1.39 \\
\hline
\end{tabular}

Table 4. Mix design

\begin{tabular}{|c|c|c|}
\hline number & curing material & dosage $(\%)$ \\
\hline A & \multirow{3}{*}{$\begin{array}{c}\text { new curing } \\
\text { agent }\end{array}$} & 6 \\
\hline B & & 7.5 \\
\hline $\mathrm{C}$ & & 10 \\
\hline $\mathrm{D}$ & \multirow{3}{*}{ P.O42.5 cement } & 6 \\
\hline E & & 7.5 \\
\hline $\mathrm{F}$ & & 10 \\
\hline
\end{tabular}

\subsection{Characteristic analysis of solidified soil}

\subsubsection{Unconfined compressive strength}

The change of unconfined compressive strength of solidified soil with age and dosage is shown in Fig. 1 and Fig. 2.

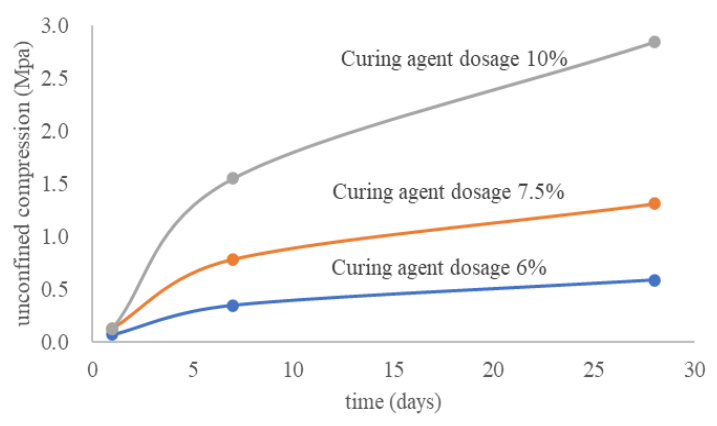

(a) New curing agent solidified soil

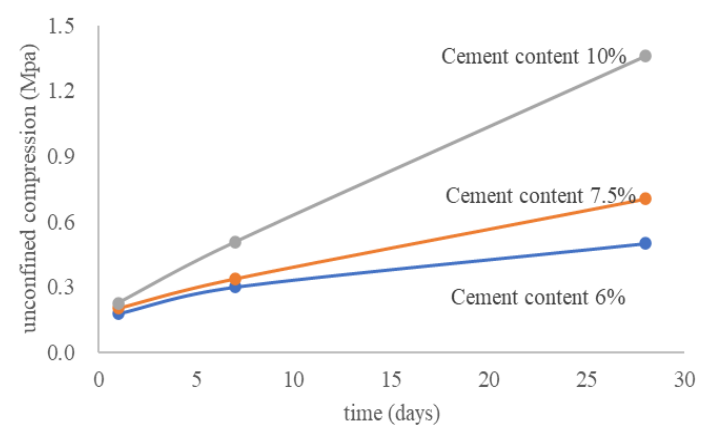

(b) Cement stabilized soil

Fig. 1. Unconfined compressive strength of solidified soil

Compared with P.0 42.5 cement stabilized soil, the $24 \mathrm{~h}$ unconfined compressive strength of the new curing agent-cured soil is smaller, only 0.07 0.13 MPa. Smaller initial strength can make the solidified soil maintain better fluidity or plasticity in the early stage of formation, which is convenient for construction. After 24 hours, the unconfined compressive strength of the new curing agent solidified soil increased rapidly, and the growth rate was significantly greater than that of the cement solidified soil, and within the range of $6 \%$ to $10 \%$, the higher the content, the faster the growth rate. The rapid increase in 
strength at this stage can quickly form a working layer, which is convenient for later construction. At $7 \mathrm{~d}$, the unconfined compressive strength of the new curing agent is significantly greater than that of cement-solidified soil. From $7 \mathrm{~d}$ to $28 \mathrm{~d}$, the growth rate of the unconfined compressive strength of the new solidified soil slowed down, slower than that of the cement solidified soil. In the range of $6 \% \sim 10 \%$, the content of the new curing agent has a great influence on the strength. The higher the content, the greater the unconfined compressive strength. The unconfined compressive strength of the $10 \%$ solidified soil is 4.8 times the $6 \%$ content. The higher the content, the greater the difference between the strength of the new curing agent and the P.0 42.5 cement-solidified soil. The $28 \mathrm{~d}$ unconfined compressive strength of $10 \%$ of the solidified soil is 2.1 times that of the same content of cement-solidified soil. The $28 \mathrm{~d}$ unconfined compressive strength of the solidified soil is 1.2 times that of the same cement solidified soil.

\subsubsection{Granularity characteristics}

A laser particle size distribution analyzer was used to conduct particle analysis tests on the 28-day solidified soil samples. The test results are shown in Table 5. After the solidified material is added to the soil, the crystals and gel formed by the hydration reaction adhere to the soil particles, the content of clay particles is significantly reduced, and the particles of 0.075 to $0.005 \mathrm{~mm}$ increase. Compared with cement, the effect of reducing the clay content of the cured soil with the new curing agent is more obvious, indicating that the new curing material can form a more stable colloid or crystal with the fine particles in the soil.

Table 5. Particle composition (\%)

\begin{tabular}{|c|c|c|c|}
\hline material & $0.25 \sim 0.075 \mathrm{~mm}$ & $0.075 \sim 0.005 \mathrm{~mm}$ & $<0.005 \mathrm{~mm}$ \\
\hline soil & 8.9 & 59.7 & 31.4 \\
\hline A & 6.0 & 71.0 & 23.0 \\
\hline D & 6.2 & 65.8 & 28.0 \\
\hline
\end{tabular}

\subsubsection{Micro test}

The $28 \mathrm{~d}$ samples of the new curing agent-cured soil A and cement-cured soil D were microscopically tested. Scanning electron microscope (SEM) was used for the test equipment. The pictures with magnifications of 10000 times and 50000 times are shown in Figure 2 and Figure 3. A large number of hexagonal plate-shaped calcium hydroxide crystals $\mathrm{CH}$, fibrous hydrated calcium silicate gel C-S-H and needle-shaped ettringite appeared in the solidified soil, superimposed on each other. Compared with cement-solidified soil, the new-type solidifying agent forms more calcium hydroxide crystals $\mathrm{CH}$ and hydrated calcium silicate gel, with fewer pores and a denser structure.

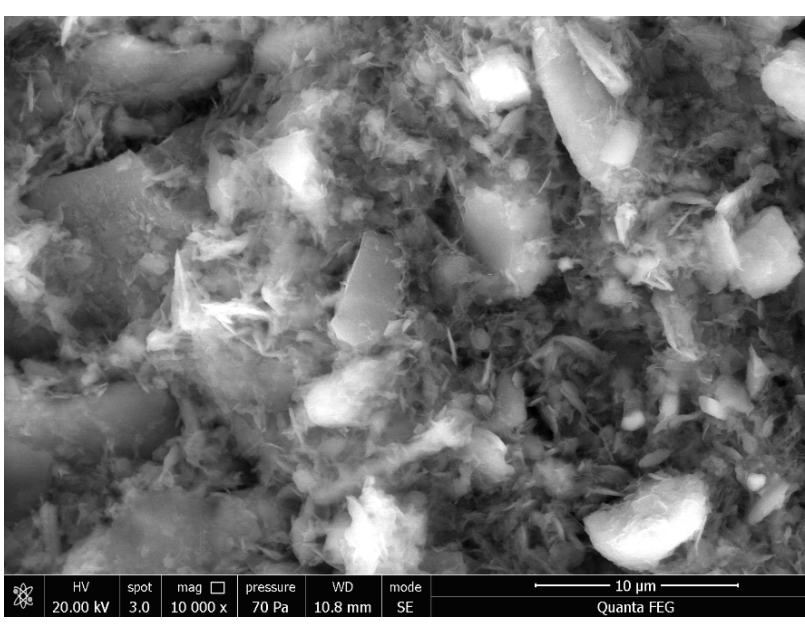

(a) A

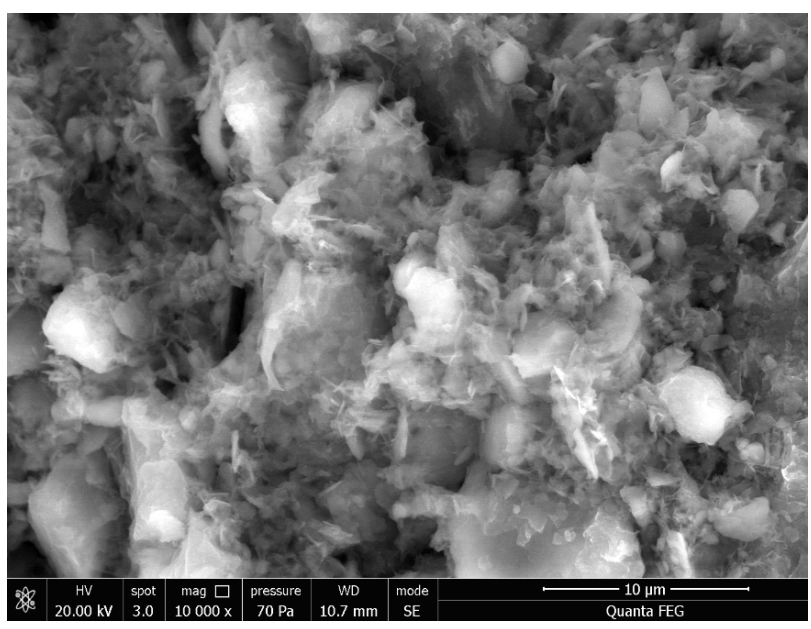

(b) $\mathrm{D}$

Fig. 2. SEM test results (10000 times)

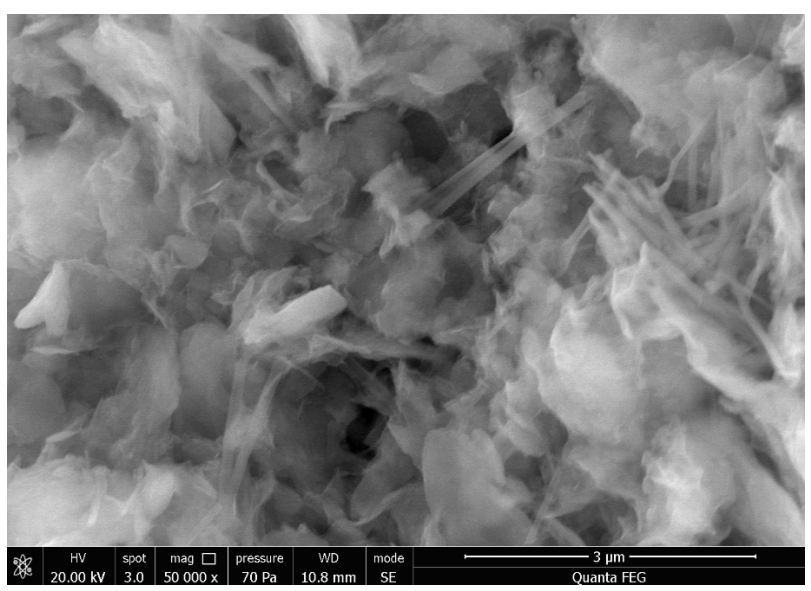

(a) $\mathrm{A}$ 


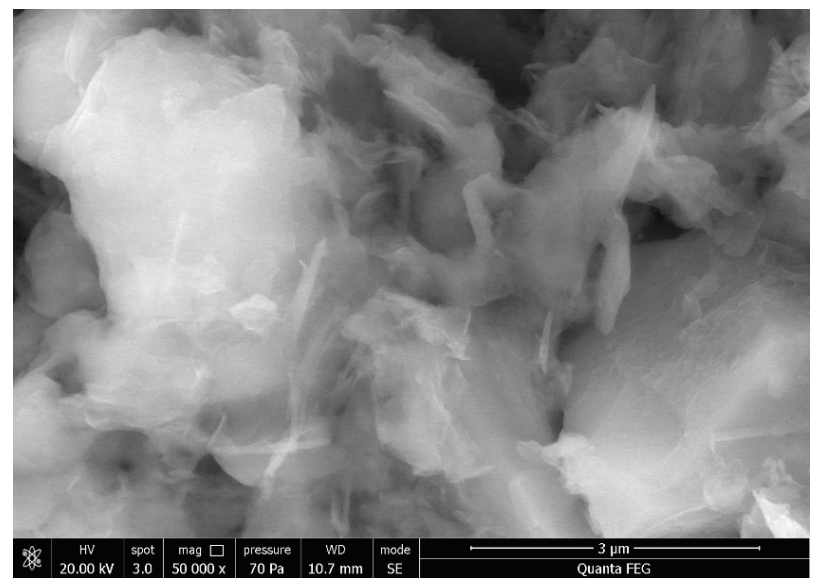

(b) D

Fig. 3. SEM test results (50000 times)

\section{Conclusion}

(1) The specific surface area of the new curing agent is significantly higher than that of P.O 42.5 cement, and the content of particles smaller than $3 \mu \mathrm{m}$ and $10 \mu \mathrm{m}$ is slightly higher than that of cement. The other particle groups are not much different. The curing agent has better hydration reaction effect than cement.

(2) The initial strength of the cured soil with the new curing agent is small, which can make the cured soil maintain good fluidity at the initial stage of formation and facilitate construction. After 24 hours, the unconfined compressive strength of the soil cured by the new curing agent increased rapidly, and the growth rate was significantly greater than that of the cement cured soil.

(3) The new curing agent solidified soil can significantly increase the strength of the solidified soil. The $28 \mathrm{~d}$ unconfined compressive strength of the $10 \%$ solidified soil is 2.1 times that of the same cement solidified soil. The dosage of the new curing agent has obvious influence on the strength, the higher the dosage, the greater the unconfined compressive strength.

(4) The basic structure of the new-type curing agent solidified soil is the same as that of cement-solidified soil, but because the new-type solidifying agent solidified soil forms more calcium hydroxide crystals $\mathrm{CH}$ and hydrated calcium silicate gel, there are fewer pores and a more structured soil. Dense.

(5) The test clay used the typical soft clay of Tianjin Port, and its strength increased significantly after curing, indicating that the new curing agent has a good curing effect on soft clay.

\section{References}

1. X. Fang, S. Sun, Z. Chen, Rock and Soil Mechanics, 27:1545-1548(2006)

2. C. Yao, W. Li, D. Lin, Journal of Engineering of Heilongjiang University, 37: 27-29(2010)

3. L. Zhu, L Wang, D. Cheng, et al, Bulletin of the Chinese Ceramic Society, 35: 2281-2286(2016)
4. X. Huang, S. Xu, J. Ning, Chinese Journal of Rock Mechanics and Engineerin, 26:156-161(2007)

5. Y. Du, F.Jin, S. Liu, Rock and Soil Mechanics, 32: 116-123 (2011)

6. H. Fan, J.Gao, P. Wu, et al, Rock and Soil Mechanics, 31: 3741-3745(2010)

7. R. Chen, Z. Wang, L. Wang, Journal of WuhanUniversity of Technology, 34: 25-29(2012)

8. Horpiulsuk S, Rachan R, Raksachon Y, Soils and Foundations, 49: 85-98(2009) 